Research Article

\title{
Numerical Simulation of Stepped Spillways with Front Step Deformation
}

\author{
Guodong Li (D), Haifeng Zhang, Xingnan Li, Lihao Guo, Yanyan Gao, and Dandan Cai \\ State Key Laboratory of Eco-Hydraulics in Northwest Arid Region of China, School of Water Resources and Hydropower, \\ Xi'an University of Technology, Xi'an 710048, China
}

Correspondence should be addressed to Guodong Li; gdli2008@xaut.edu.cn

Received 22 July 2020; Revised 22 February 2021; Accepted 19 March 2021; Published 30 March 2021

Academic Editor: Fausto Arpino

Copyright () 2021 Guodong Li et al. This is an open access article distributed under the Creative Commons Attribution License, which permits unrestricted use, distribution, and reproduction in any medium, provided the original work is properly cited.

In order to solve the flood discharge problem of both small- and medium-sized warping dams in the Loess Plateau, a stepped spillway scheme, based on an ecological bag, to achieve full-section water flow and energy dissipation has been proposed in this paper. The hydraulic and energy dissipation characteristics of a stepped spillway layout scheme were studied using 3D numerical simulation. As the height of the dams is low and the spillways are short, the research has shown that the traditional single-step layout scheme leads to a low overall energy dissipation rate due to the small amount of energy dissipated in the initial steps. As a result of this, this paper has put forward two kinds of step layout schemes such as the shunt type and the staggered type for the initial steps. Through analysis of the flow state, the pressure distribution, and the total energy dissipation rate, the results have shown that shunt type and staggered type with front step deformation produced an obvious mixing of the water flow, fewer negative pressure areas, and a higher energy dissipation rate. The optimal energy dissipation rate of the staggered type reached $87.75 \%$, and the maximum energy dissipation rate was increased by $27.97 \%$.

\section{Introduction}

Located in the north of central China, the Loess Plateau is one of the four major plateaus in China. The soil here is loose and soil erosion is serious, especially in northern Shaanxi. A warping dam is an effective soil and water conservation project; they can not only reduce soil erosion but also prevent warping and reclaim land to increase grain production. Warping dams are important engineering measures that are used to control soil erosion in northern Shaanxi and maintain the ecological environment of the Loess Plateau. However, with the passage of time, the early construction sections of warping dams gradually fill up; this is a particular risk in small- and medium-sized warping dams because they do not have a spillway. Therefore, adding dam overflow facilities has become an urgent problem to ensure the safety of warping dams. For small- and mediumsized warping dams, the construction of traditional concrete spillways is not only costly and difficult to manage but also incompatible with the concept of modern ecological protection. Therefore, there is an urgent need for a new solution to the problem of warping dams overflowing.
The mechanism of overflow earth dam is very complicated, and research on this aspect is very limited. From 1981 to 1986, the U.S. Bureau of Reclamation conducted a flexible lining (geomembrane) extraordinary spillway experiment at the Cottonwood Dam, the results of which were relatively successful [1]. Zheng [2] studied the use of an asphalt protective surface to increase the safety of water flowing over the dam's surface. Chen [3] studied the protective effect of a grass planting surface, which is very compatible with the concept of ecological and environmental protection. Some scholars also analyzed the seepage of an earth dam and the stability of its slope [4-7]. Generally speaking, the main methods of water crossing are local water crossing and full-section water crossing of a dam. The main protection for the dam's surface is divided into hard protective surfaces, such as concrete, and flexible protective surfaces, such as vegetation [8]. With local overflow, unit width discharge will be relatively large, and it is difficult to dissipate energy when the water flows downstream. With the use of concrete and other hard surfaces, the foundation will be higher and the cost of construction will be higher [9]. Therefore, according to the characteristics of a 
warping dam on the Loess Plateau, full-section flow of the dam has been adopted, and an ecological bag has been used to construct the stepped spillway to protect the flexible slope.

The stepped spillway drainage structure dates back to 2500 years ago [10], and it has good energy dissipation; it can greatly shorten the length of the stilling pool and reduce the project's investment costs. With the development of roller concrete damming technology, this technique has been widely applied [11], and scholars both at home and abroad have conducted in-depth studies on it $[12,13]$. Wu et al. [14] found that the location of the inception point of the air entrainment for the stepped spillway is much nearer to the top of the spillway than a smooth spillway, which led to the high energy dissipation ratio of the stepped spillway. Eghbalzadeh and Javan [15] and Kositgittiwong et al. [16] analyzed the models that are commonly used in the numerical simulation software and found that each turbulence model is able to accurately simulate the flow pattern. Chanson et al. $[17,18]$ found that the scaling effect of a stepped spillway was more significant; therefore, more attention should be paid to the model tests. Tian [19-21] analyzed the energy dissipation rate of a stepped spillway under sliding, falling, and transition flow conditions. Under the experimental conditions, the energy dissipation rate of the three types of flow conditions was not significantly different. Salmasi and Samadi [22] and Zhang et al. [23] studied the flow pattern and flow pressure of a stepped spillway and found that vortex flow is the key to solving those problems. Mojtahedi et al. [24] came up with a type of the fuzzy inference system (FIS) which was used to study the control of the rates of dissipation. It can lead to a remarkable reduction in the dimensions of stilling basins. Azman et al. [25] studied the effect of barrier height on stepped spillway design and found that the usage of the higher barrier would promote the occurrence of substantial air entrainment during water swirling that will increase the power dissipation in flow. These studies have promoted the development of stepped spillways. However, from the normal research on stepped spillways, it can be seen that the energy dissipation rate at the front step is low. It had little influence on the high dam with long spillway but had great influence on the small- and medium-sized dam with short spillway length. In order to get better energy dissipation of small- and medium-sized dams with short spillway length, we deformed the front step.

At present, most of the small- and medium-sized warping dams on the Loess Plateau are low dams with a short overflow length. With the construction of an ecological bag, its anti-impact flow rate will be lower. Therefore, this paper has studied the layout of a stepped spillway, constructed for small- and medium-sized warping dams on the Loess Plateau according to their characteristics from the numerical simulation.

\section{The Establishment and Verification of the Numerical Model}

2.1. Experimental Verification. The flume equipment of the hydraulics laboratory of the Xi'an University of Technology was used for the test model. The structural diagram is shown in Figure 1.
The water in the reservoir flows through the pump and the underground pipe into the spillway. After the aeration section, the water flows through the U-shaped return tank and then enters the underground reservoir. The start of the whole test section is the WES weir, and the end is the ogee section. The dam height is $186.63 \mathrm{~cm}$, and the step height is $5 \mathrm{~cm}$. The slope of the spillway is $30^{\circ}$, and the width is $25 \mathrm{~cm}$. The WES weir is composed of three composite arcs, the radii of which are $10 \mathrm{~cm}, 4 \mathrm{~cm}$, and $0.8 \mathrm{~cm}$, respectively, the radius of the ogee section is $70 \mathrm{~cm}$, and the shooting angle at the bottom of the arc is 20 degrees.

2.2. Numerical Model. In this paper, Ansys Fluent has been used to simulate and calculate the hydraulic characteristics of the energy dissipation of a stepped spillway. Before numerical simulation, the meshing and grid independence study and the turbulence model study are important steps to ensure the calculation results. In order to select a suitable turbulence model, taking working condition 3 (weir head $h=0.3 \mathrm{~m}$ and unit width discharge $q=0.3502 \mathrm{~m}^{2} / \mathrm{s}$ ) as an example, three turbulence models, standard $k$ - $\varepsilon$, realizable $k$ $\varepsilon$, and RNG $k-\varepsilon$, were selected to calculate the pressure. The results were compared with the experimental data. The calculation results are shown in Table 1. The horizontal length of stage $L=260 \mathrm{~cm}$. It can be seen that the RNG $k-\varepsilon$ turbulence model is the closest to the experimental dates, and the relative errors are less than 5\%. Therefore, the RNG $k-\varepsilon$ turbulence model is selected for calculation.

The model and boundary conditions are shown in Figure 2.

The mesh was divided into a combination of unstructured tetrahedral elements and structured hexahedral elements according to the parameters of the grid convergence factor (GCI) proposed by Roache [26] and in order to evaluate the discrete error of the calculation results. The calculation results are shown in Table 2.

The results have shown that the convergence factors of the grid gradually decrease with the encryption of the grid, and all of them are less than 5\%. The discrete error is small, and the influence of the grid on the computational flow is small. Therefore, the comprehensive consideration accuracy, the computer's running condition, and a mesh size of $0.1 \mathrm{~cm}$ was selected to divide the model. A detailed mesh generation effect is shown in Figure 3.

2.3. Comparing the Simulated Values to the Experimental Values. We compared the horizontal pressure, vertical pressure, and pressure along the steps to verify the accuracy of the simulation. The horizontal length of stage $L=260 \mathrm{~cm}$, step length $b=8.66 \mathrm{~cm}$, and step height $a=5 \mathrm{~cm}$. The working conditions are shown in Table 3.

Taking fifteenth step for working condition 3 as an example, the horizontal and vertical pressure distributions of the steps were analyzed, and the simulated values were then compared with the experimental values. The results are shown in Figure 4, and the pressure distribution along the step is shown in Figure 5. 


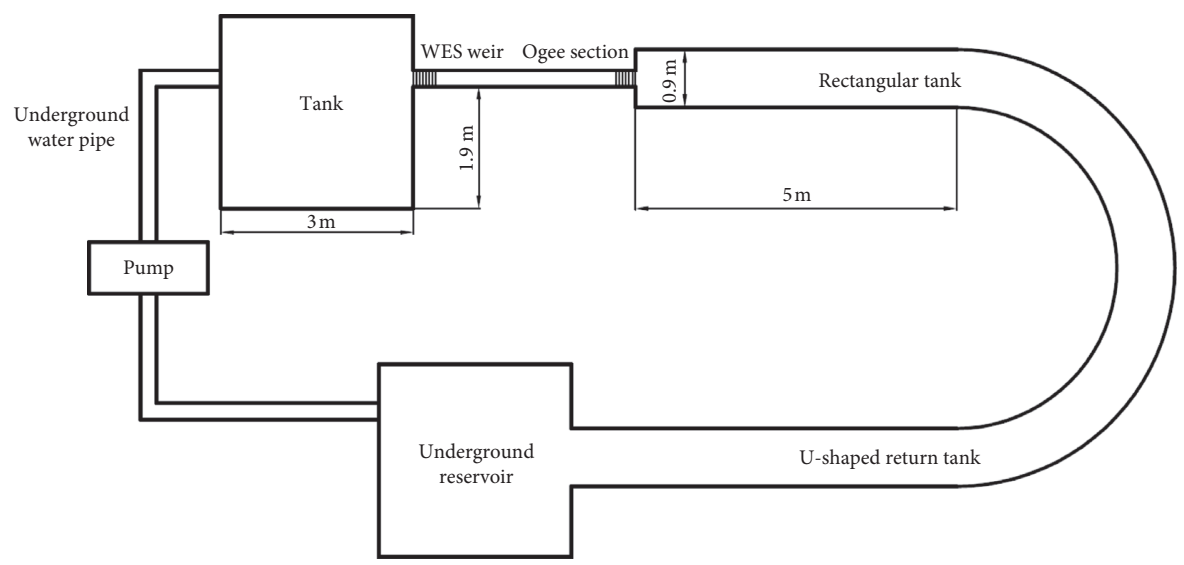

(a)
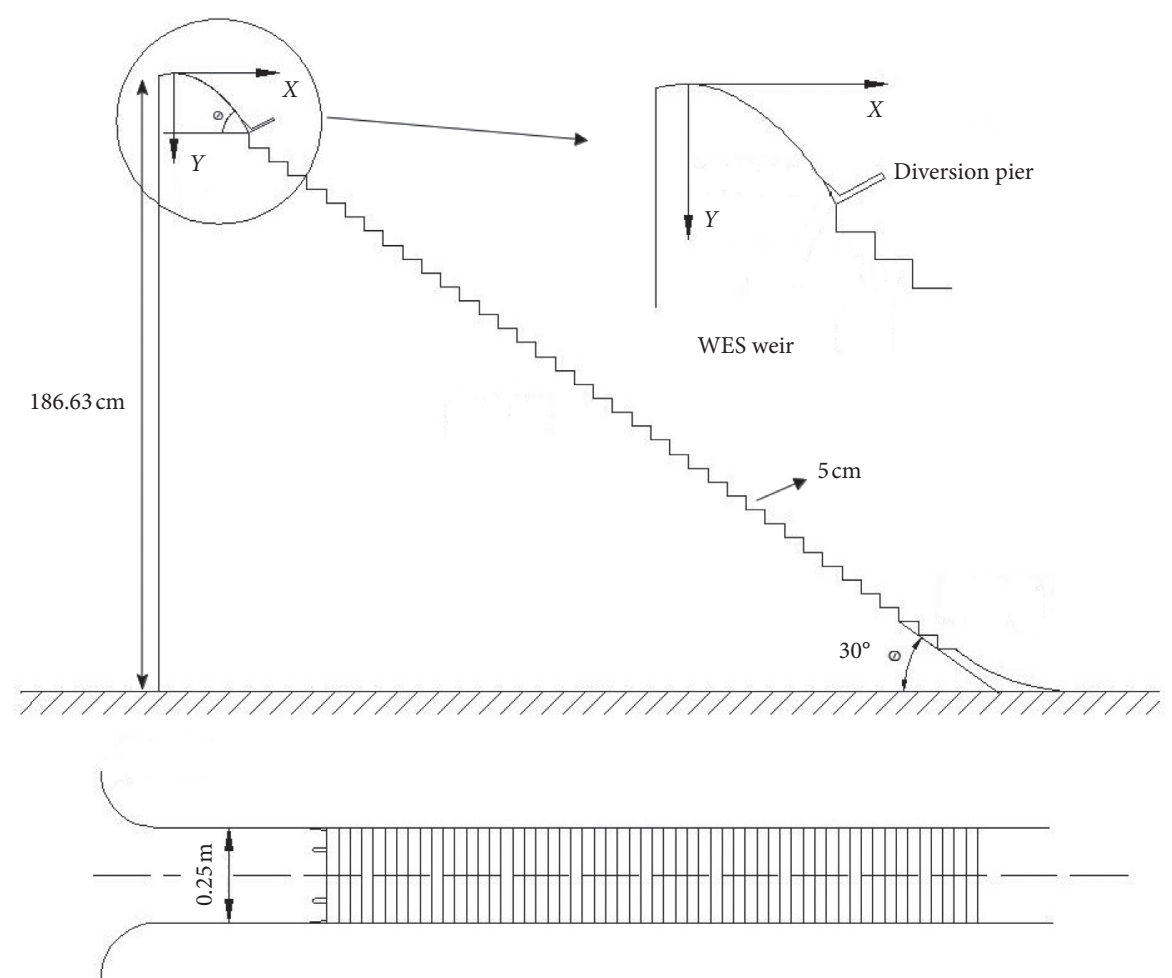

(b)

FIGURE 1: Schematic diagram of the spillway model.

TABLE 1: Comparison between the calculated results of each turbulence model and the experimental data.

\begin{tabular}{lcccccc}
\hline \multirow{2}{*}{ Turbulence model } & \multicolumn{2}{c}{$x / L=0.4$} & \multicolumn{2}{c}{$x / L=0.6$} & \multicolumn{2}{c}{$x / L=0.8$} \\
& Pressure $(\mathrm{Pa})$ & Relative error (\%) & Pressure (Pa) & Relative error (\%) & Pressure (Pa) & Relative error (\%) \\
\hline$k-\varepsilon$ standard & 523.6 & 12.4 & 875.2 & 13.0 & 625.1 & 13.2 \\
$k-\varepsilon$ realizable & 515.2 & 13.8 & 685.3 & 11.5 & 858.6 & 19.2 \\
$k-\varepsilon$ RNG & 573.5 & 4.1 & 784.2 & 1.3 & 739.9 & 2.7 \\
Experimental data & 597.8 & - & 774.2 & - & 720.3 & - \\
\hline
\end{tabular}




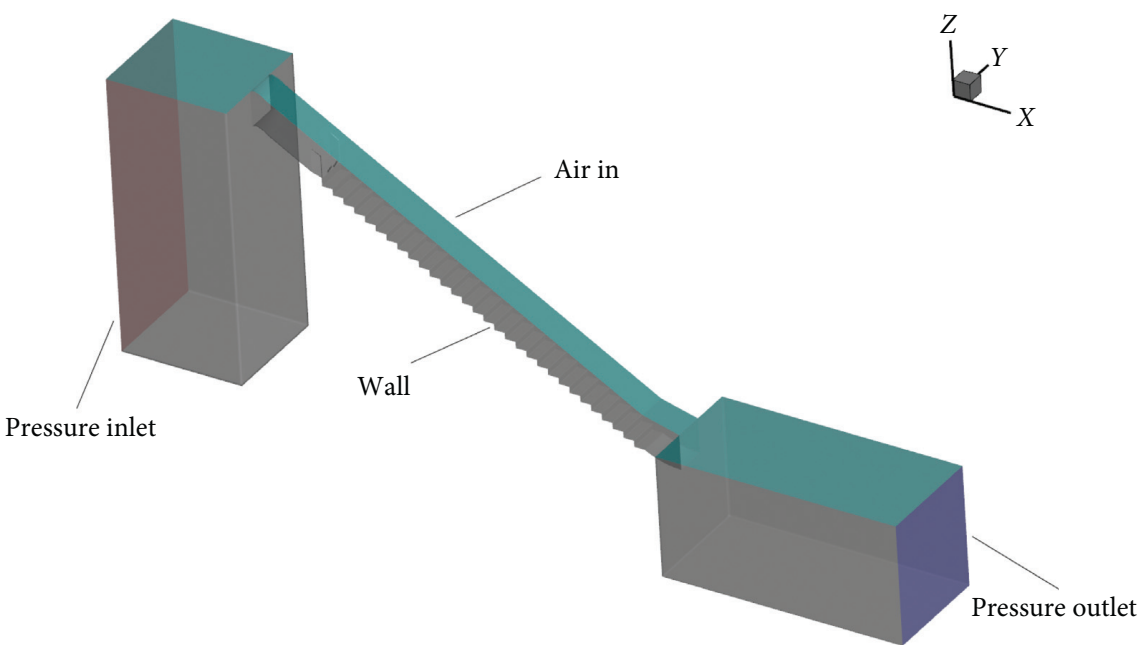

FIGURE 2: Boundary condition diagram of the model.

TABLE 2: Calculation results of GCI.

\begin{tabular}{lcccccc}
\hline Mash size $(\mathrm{cm})$ & Total grid & $P$ & $F_{s}$ & $Q\left(\mathrm{~kg} / \mathrm{m}^{3}\right)$ & $R$ & Relative error $\eta$ \\
\hline 0.1 & 454370 & 0.001 & 1.25 & 2303.163 & - & - \\
0.04 & 756090 & 0.001 & 1.25 & 2430.521 & 2.5 & 0.0524 \\
0.02 & 1116240 & 0.001 & 1.25 & 2406.308 & 2 & 0.0101 \\
\hline
\end{tabular}

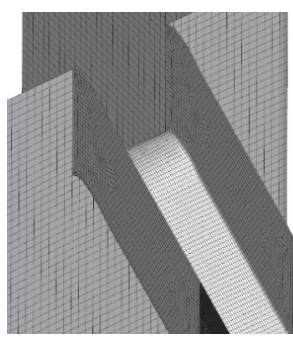

(a)

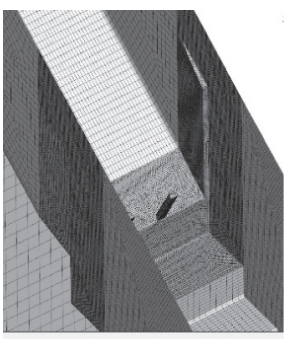

(b)

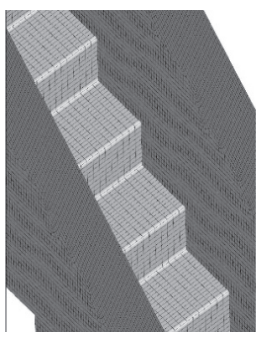

(c)

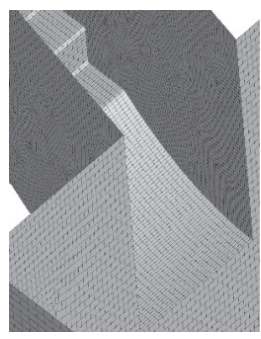

(d)

Figure 3: Grid detail diagram of the stages.

TABLE 3: Conditions for the simulation calculations.

\begin{tabular}{lccr}
\hline Working condition & Unit width discharge $\left(\mathrm{m}^{2} / \mathrm{s}\right)$ & Weir head $(\mathrm{m})$ & \\
\hline 1 & 0.0585 & 0.1 & \\
2 & 0.1809 & 0.2 & 4.73 \\
3 & 0.3502 & 0.3 & 2.84 \\
\hline
\end{tabular}

Equations (1)-(4) were used to calculate the energy dissipation rate. The experimental and simulated results are shown in Figure 6.

$$
\begin{gathered}
\eta=\frac{\Delta E}{E_{1}} \times 100 \%, \\
\Delta E=E_{1}-E_{2}, \\
E_{1}=Z_{1}+H_{1} \cos \theta+\alpha_{1} \frac{\nu_{1}^{2}}{2 g},
\end{gathered}
$$

$$
E_{2}=H_{2} \cos \theta+\alpha_{2} \frac{v_{2}^{2}}{2 g},
$$

where $Z_{1}$ is the elevation of the upstream section (m); $H_{1}$ is the upstream water level $(\mathrm{m}) ; H_{2}$ is the downstream water level $(\mathrm{m}) ; \nu_{1}$ is the average upstream velocity $(\mathrm{m} / \mathrm{s}) ; \nu_{2}$ is the average downstream velocity $(\mathrm{m} / \mathrm{s}) ; \alpha$ is the velocity coefficient, $\alpha=1$; and $\theta$ is the slope angle.

From Figures 4-6, it can be concluded that the values for the numerical simulation are in good agreement with the experimentally measured values and energy dissipation rate 


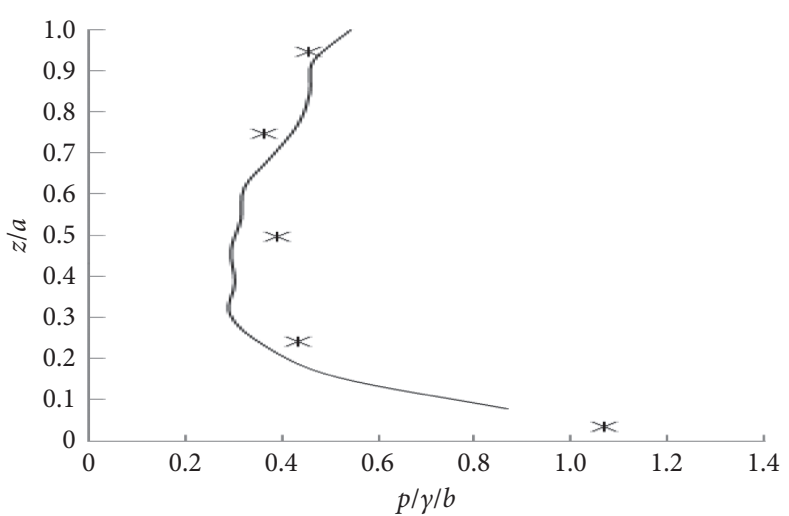

* EXP

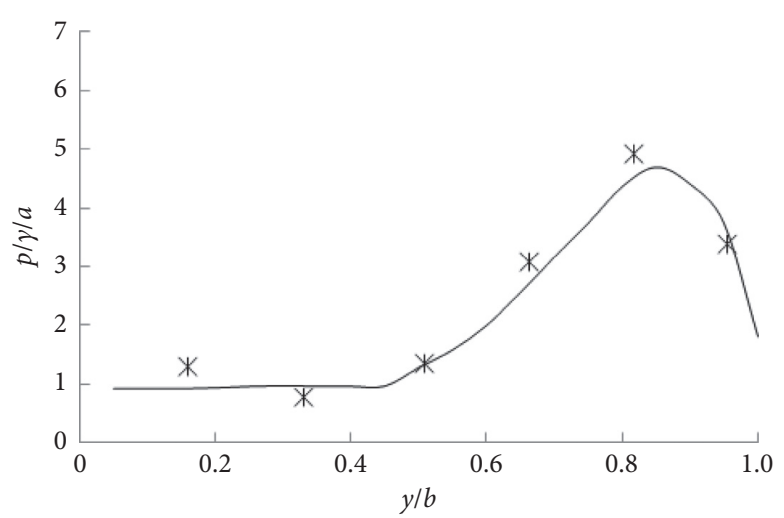

* EXP

(a)

(b)

Figure 4: Comparison of the simulated and experimental pressure values for the vertical and horizontal plane of fifteenth step: (a) the pressure on the level of the step; (b) the pressure on the vertical plane of the step.

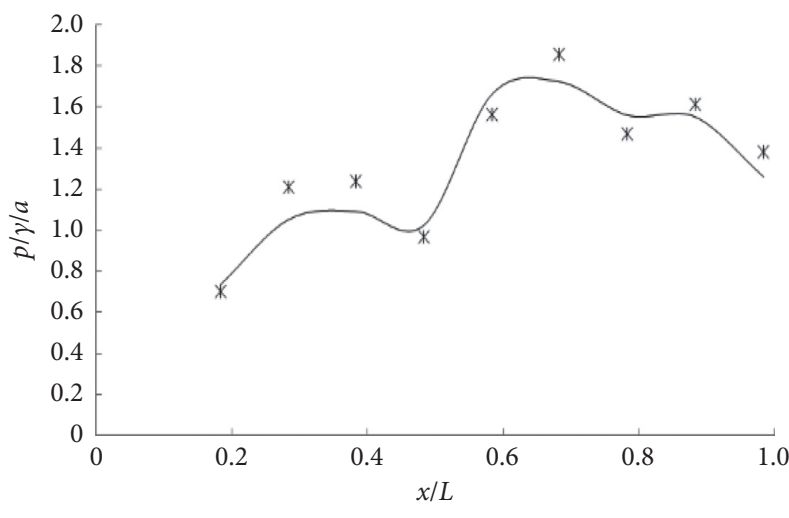

* EXP

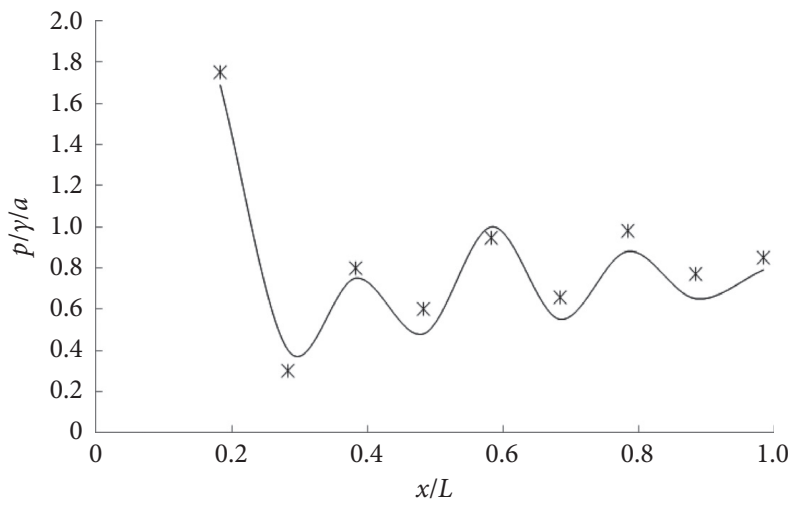

* EXP

(a)

(b)

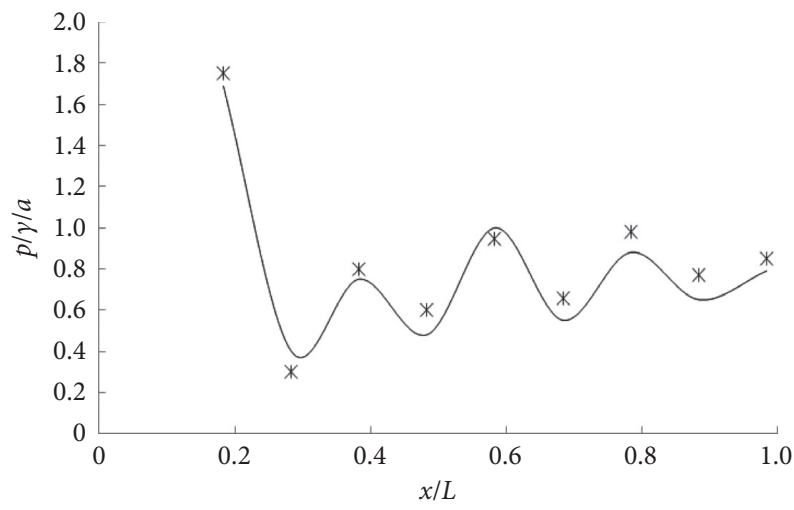

* EXP

CFD

(c)

Figure 5: Comparison of the simulated and experimental values of the mean pressure distribution along the step: (a) $\mathrm{Fr}=2.16$; (b) $\mathrm{Fr}=2.84$; (c) $\mathrm{Fr}=4.73$. 


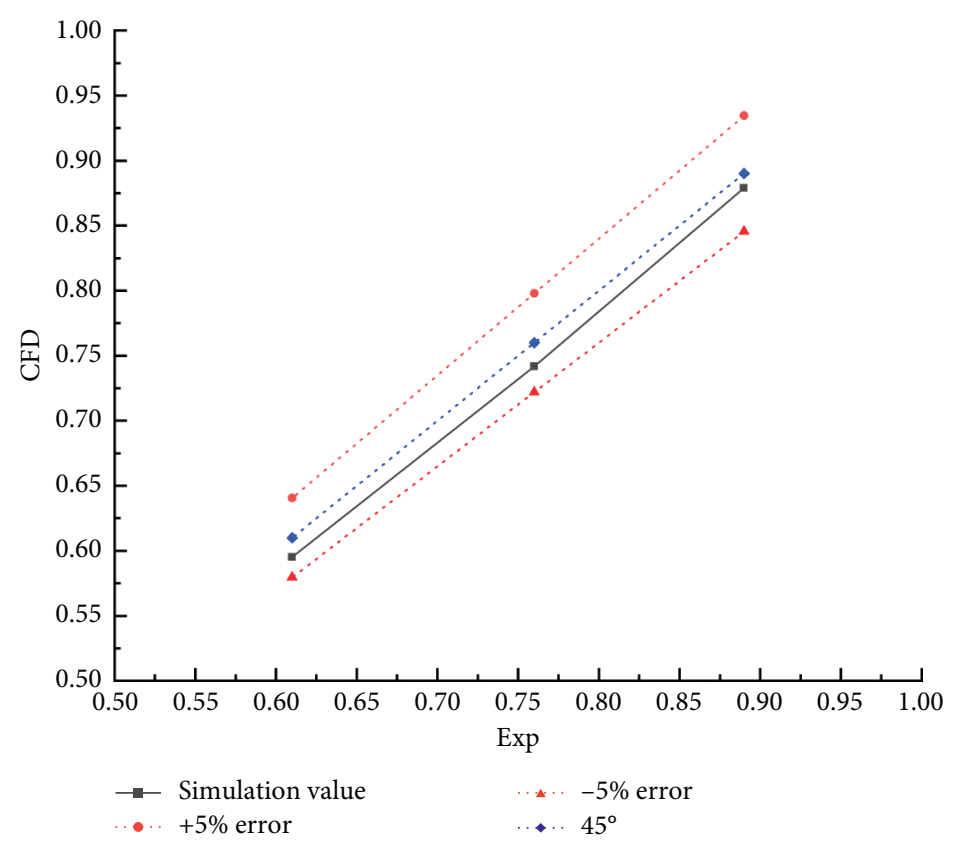

FIgURE 6: Comparison of the simulated and experimental energy dissipation rates.

error is within 5\%; thus, the reliability and accuracy of the simulation have been verified.

\section{Establishing the Step Scheme}

3.1. Traditional Stepped Spillway. The model of this numerical simulation took an earth dam in the Loess Plateau region as the prototype, and the scheme was established. The length of the dam was $1 \mathrm{~m}$, which is an arrangement unit. The backwater slope ratio and the upstream slope ratio were chosen to be $1 / 2$. The height of the steps was $a=0.5 \mathrm{~m}$, and the width was $b=1 \mathrm{~m}$. Type 1 was a traditional stepped spillway without front step deformation, as shown in Figure 7.

According to the characteristics of warping dams in the Loess Plateau region and in order to make the research results fundamentally cover the characteristics of the dams in the Loess Plateau region, different heights of the dam were selected as $15 \mathrm{~m}, 30 \mathrm{~m}$, and $45 \mathrm{~m}$. For the different heights, the dams were analyzed under a single width flow of $2.5 \mathrm{~m}^{2}$ / $\mathrm{s}, 4.5 \mathrm{~m}^{2} / \mathrm{s}$, and $5.5 \mathrm{~m}^{2} / \mathrm{s}$. The specific simulated conditions are shown in Table 4 .

According to the simulated results, the energy dissipation rate for the type 1 was calculated using equations (1)-(4), and the results are shown in Table 5.

It can be seen from the results that energy dissipation in the case of small flow performed well, but once the water flow increases, its energy dissipation was significantly reduced. This was because the warping dams on the Loess Plateau are generally low in height. When the velocity of the water flow increases, the initial stage does not have a significant effect. The results have shown that a low energy dissipation rate in the initial stage leads to a low overall energy dissipation rate. In order to solve this problem, deformation of the front step of the spillway has been proposed in this paper so that it can effectively dissipate energy in the initial steps.

3.2. Shunt Type and Staggered Type. In order to obtain a better energy dissipation effect, front step deformation was carried out, and both a shunt type and staggered type have been labeled type 2 and type 3, as shown in Figures 8 and 9. The length of the dam was $4.5 \mathrm{~m}$, which is an arrangement unit.

\section{Results and Discussion}

4.1. Flow Pattern. Since the focus of this paper has been on the initial step flow, the dam heights of $H=30 \mathrm{~m}$ and $q=4.5 \mathrm{~m}^{2} / \mathrm{s}$ were chosen to analyze the initial step flow, as shown in Figure 10.

In Figure 10, the surface of the water in type 1 was relatively stable with small fluctuations along the path, and the aeration effect at the front step was not obvious, which were not conducive to the front step energy dissipation; compared with type 1 , type 2 and type 3 had significant fluctuation along the path, and the aeration effect at the front step was better. When the water flow through the steps, strong fluctuations were generated, which promoted the breaking of the water surface waves, strengthened the turbulent kinetic energy exchange between the water flow, and increased the energy dissipation at the front step. With the downward flow of water, the flow pattern gradually became stable.

4.2. Velocity Distribution. From the simulation calculation, the velocity contour lines of the stepped spillways with different shapes were obtained, for values of $H=30 \mathrm{~m}$ and $q=4.5 \mathrm{~m}^{2} / \mathrm{s}$. Since the spillways were narrow and long, the 


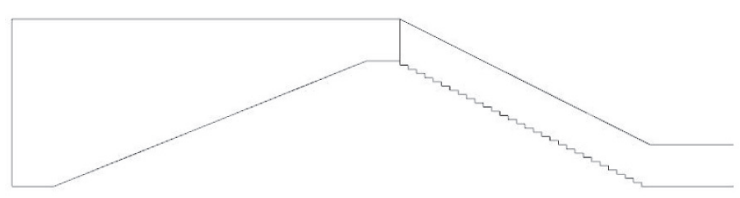

(a)

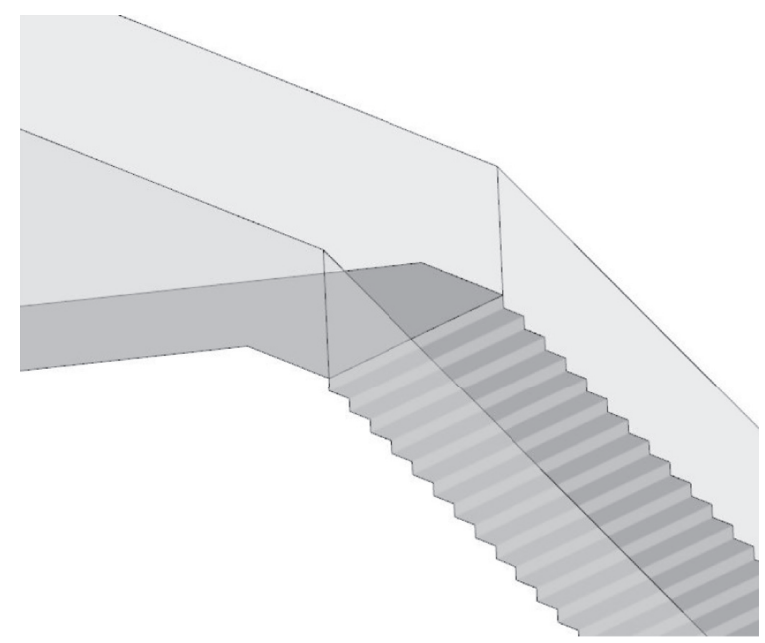

(b)

Figure 7: Type 1 spillway: (a) front view; (b) three-dimensional diagram.

TABLE 4: Design of the simulated working conditions.

\begin{tabular}{lccccc}
\hline Working condition & Dam height $(\mathrm{m})$ & Unit width discharge $\left(\mathrm{m}^{2} / \mathrm{s}\right)$ & Weir head $(\mathrm{m})$ & Velocity $(\mathrm{m} / \mathrm{s})$ & Water surface elevation $(\mathrm{m})$ \\
\hline \multirow{2}{*}{ I } & \multirow{2}{*}{15} & 2.5 & 1.316 & 1.900 & 16.316 \\
& & 4.5 & 1.947 & 2.312 & 16.947 \\
II & \multirow{3}{*}{30} & 5.5 & 2.225 & 2.472 & 17.225 \\
& & 2.5 & 1.316 & 1.900 & 31.316 \\
& & 4.5 & 1.947 & 2.312 & 31.947 \\
III & \multirow{3}{*}{45} & 5.5 & 2.225 & 2.472 & 32.225 \\
& & 2.5 & 1.316 & 1.900 & 46.316 \\
& & 4.5 & 1.947 & 2.312 & 46.947 \\
\end{tabular}

TABLE 5: Calculation results for the type 1 dam's energy dissipation rate.

\begin{tabular}{|c|c|c|c|c|c|c|c|}
\hline Type & $\begin{array}{c}\text { Dam } \\
\text { height }(m)\end{array}$ & $\begin{array}{c}\text { Unit width } \\
\text { discharge }\left(\mathrm{m}^{2} / \mathrm{s}\right)\end{array}$ & $\begin{array}{c}\text { Weir crest } \\
\text { velocity, } v_{1}(\mathrm{~m} / \mathrm{s})\end{array}$ & $\begin{array}{c}\text { Terminal } \\
\text { velocity }(\mathrm{m} / \mathrm{s})\end{array}$ & $\begin{array}{l}\text { Terminal water } \\
\text { depth }(\mathrm{m})\end{array}$ & $\begin{array}{c}\text { Terminal Froude } \\
\text { number, Fr }\end{array}$ & $\begin{array}{c}\text { Energy dissipation } \\
\text { rate, } \eta\end{array}$ \\
\hline \multirow{9}{*}{1} & \multirow{3}{*}{$H=15$} & 2.5 & 1.900 & 8.923 & 0.290 & 5.29 & 75.40 \\
\hline & & 4.5 & 2.312 & 13.459 & 0.412 & 6.69 & 46.38 \\
\hline & & 5.5 & 2.472 & 14.334 & 0.431 & 6.97 & 40.29 \\
\hline & \multirow{3}{*}{$H=30$} & 2.5 & 1.900 & 10.997 & 0.201 & 7.84 & 80.43 \\
\hline & & 4.5 & 2.312 & 15.276 & 0.425 & 7.48 & 63.08 \\
\hline & & 5.5 & 2.472 & 16.506 & 0.437 & 7.97 & 57.32 \\
\hline & \multirow{3}{*}{$H=45$} & 2.5 & 1.900 & 14.003 & 0.232 & 9.29 & 78.51 \\
\hline & & 4.5 & 2.312 & 17.069 & 0.299 & 9.96 & 68.55 \\
\hline & & 5.5 & 2.472 & 18.524 & 0.331 & 10.28 & 63.21 \\
\hline
\end{tabular}

ends of the spillways were locally amplified to facilitate observation; the contour map is shown in Figure 11.

At the end of the stepped spillways, the flow velocity followed the order of type $3<$ type $2<$ type 1 . The contour lines were more like curves or closed curves between the steps, and they were not completely parallel to the overflow surface in the main flow. The flow of the water also resulted in the presence of high-velocity gas near the surface of the water. As the depth of the water increased, the drag effect of the water was less obvious and the movement of the gas was weaker. The flow as a whole showed a great degree of disorder, and a large amount of momentum exchange occurred between the main flow and the vortices, and the amount of aeration in the incoming flow increased. When the frictional resistance of the steps could not be balanced with the increased kinetic energy of the flow, the flow velocity increased and the depth of the water decreased.

4.3. Pressure on Horizontal Step Surface. The maximum pressure for the three types of stepped spillway increased with the increase in the flow rate. The pressure on the surface of the step first decreased and then increased from the bottom angle of the previous step to its top of the next step and then decreased again past this point. The minimum value appears at about $20 \sim 40 \%$ of the step length from the 


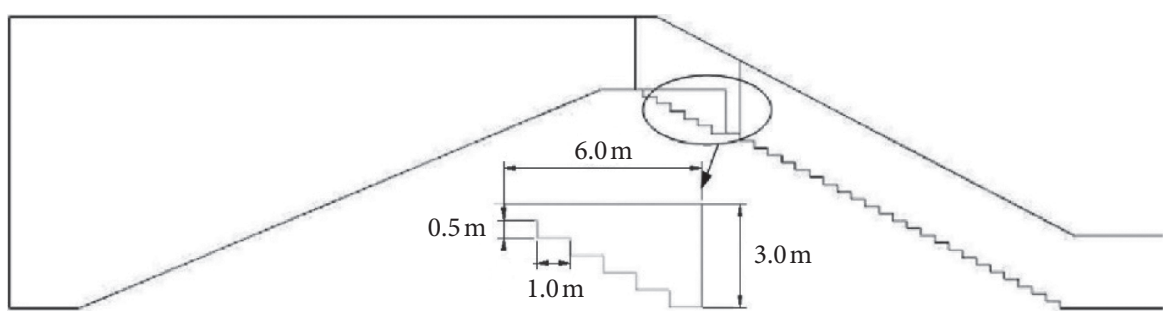

(a)

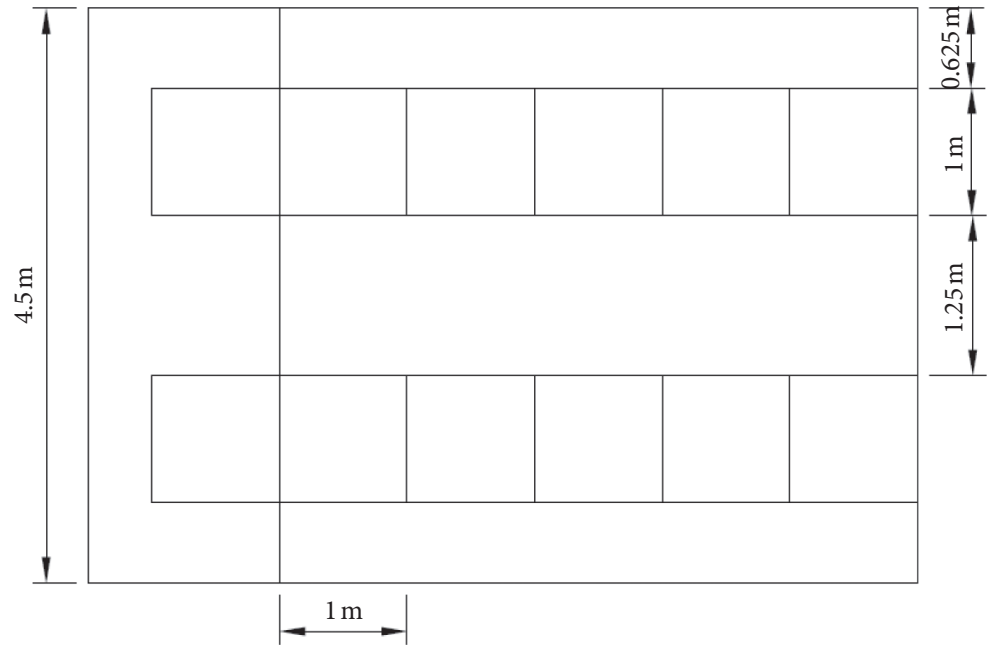

(b)

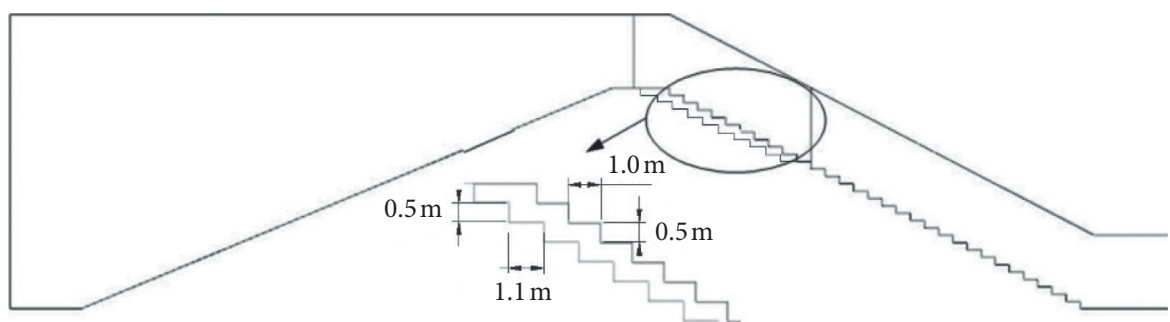

(c)

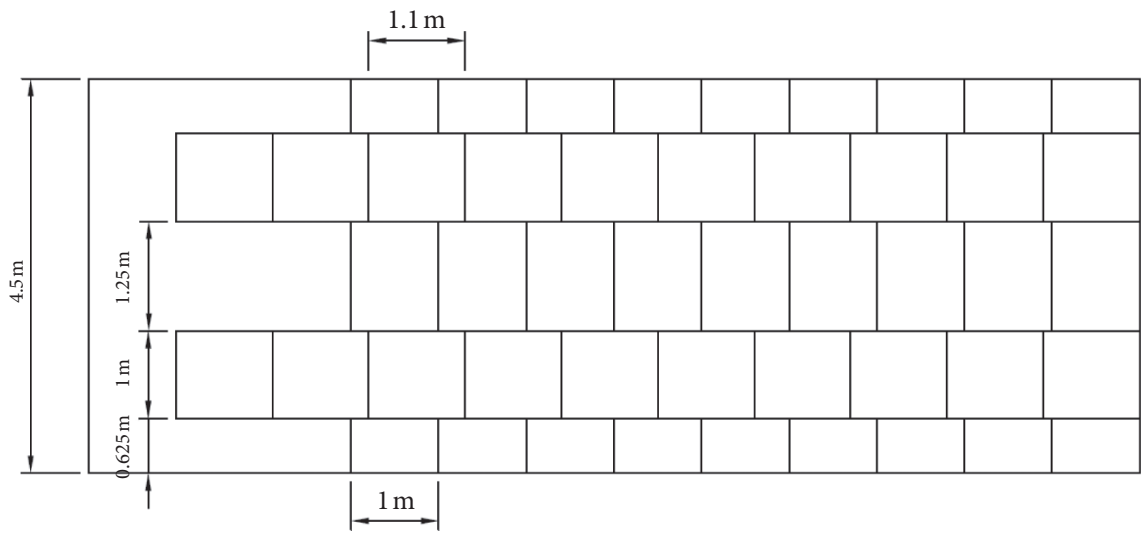

(d)

Figure 8: Front view and side view of the initial steps of the two types: (a) front view of type 1; (b) side view of the initial steps of type 1; (c) front view of type 2; (d) side view of the initial steps of type 2.

bottom of the previous step, and the maximum value appears at $80 \sim 90 \%$ of the step length. After reaching its maximum value, the pressure again decreases as the water passes the top of the next step. The main reason for this is that in the steps, during the formation of the pressure distribution of a clockwise whirlpool, a flow vortex appears on the vertical surface of the steps. When the water flows to the vertical plane of the step, it is blocked by the vertical 


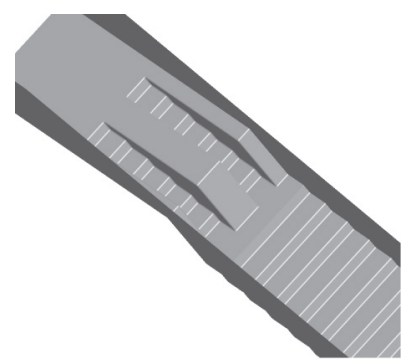

(a)

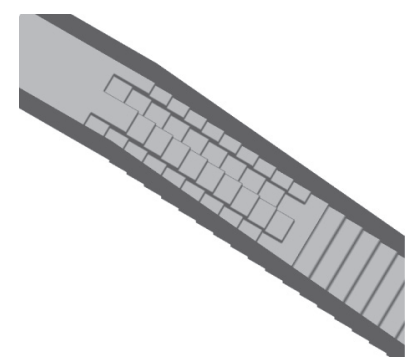

(b)

Figure 9: Three-dimensional diagrams of the two types of stepped spillway: (a) type 1; (b) type 2.

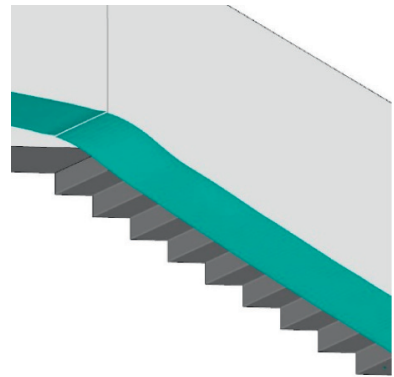

(a)

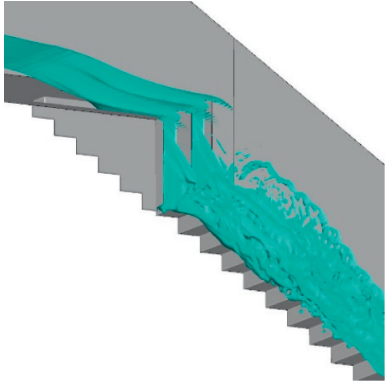

(b)

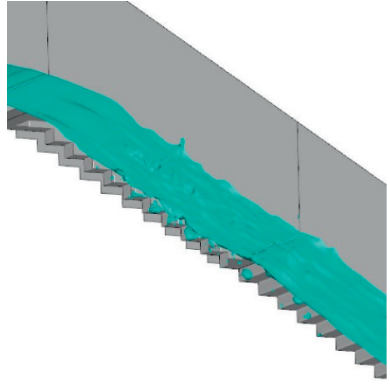

(c)

Figure 10: Flow pattern of the three types of stepped spillway $\left(H=30 \mathrm{~m}\right.$ and $\left.q=4.5 \mathrm{~m}^{2} / \mathrm{s}\right)$ : (a) type 1 ; (b) type 2 ; (c) type 3 .

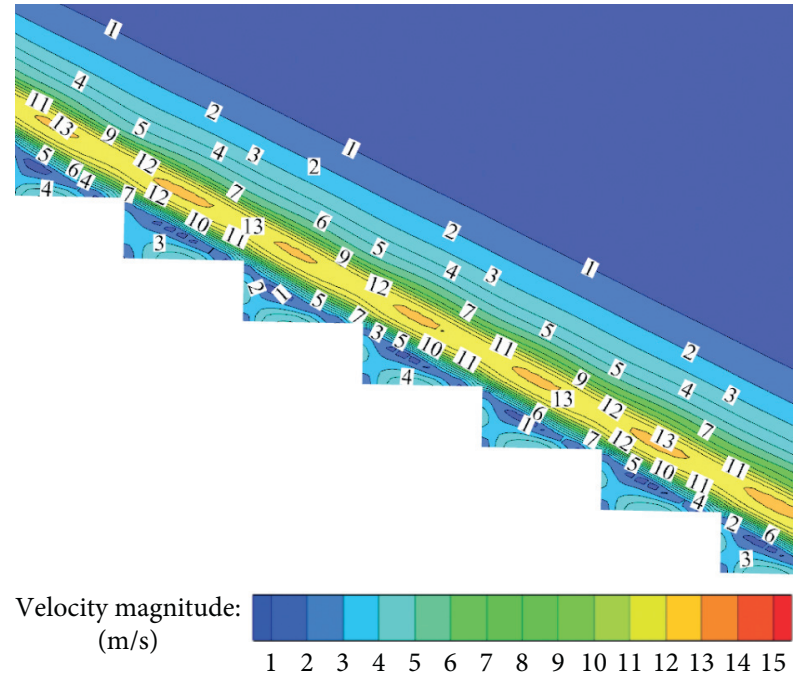

(a)

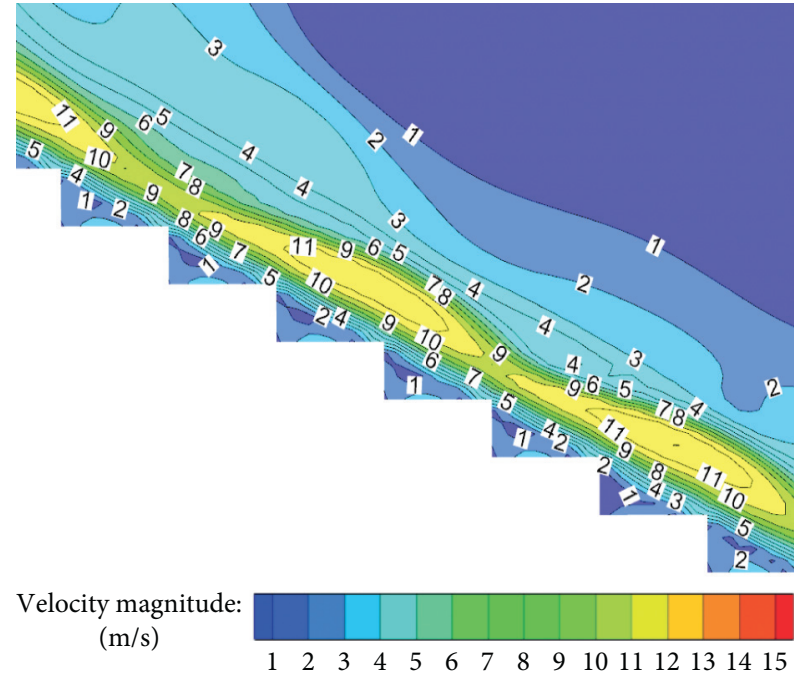

(b)

Figure 11: Continued. 


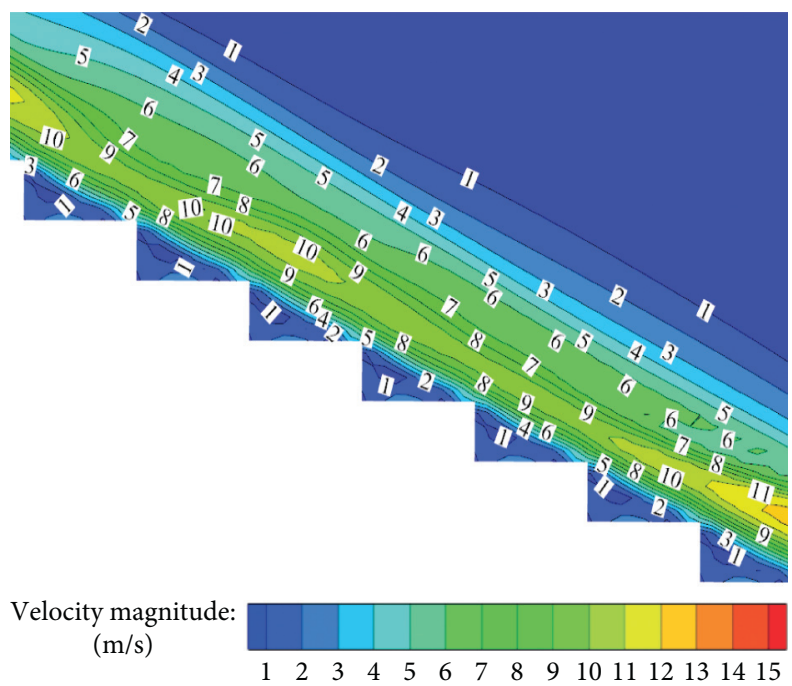

(c)

FIGURE 11: Contour maps of the end of the three types of spillways when $H=30 \mathrm{~m}$ and $q=4.5 \mathrm{~m}^{2} / \mathrm{s}$ : (a) type 1; (b) type 2; (c) type 3 .

plane of the step, which makes the water turn and counteract the incoming flow, so that the minimum pressure appears near the concave angle of the step. Then, the whirlpool water flows along the mainstream direction. Because of the rotation of the whirlpool, the water carries out an approximate vertical impact on the step surface, and the impact point is located near the convex angle of the step. Therefore, the maximum pressure on the step surface is located in the second half of the horizontal plane of the step. After the impact of the mainstream flow and the vortex shear effect of the fluid, the pressure decreased again. The horizontal pressure distribution of the three types of stepped spillway under the other working conditions is similar to that in Figure 12. Under the working conditions with a high dam height and a large flow, negative pressure will appear on some of the steps.

4.4. Pressure on Vertical Step Surface. The maximum pressure relative to the vertical surface was on the top of the steps and then decreased along the vertical orientation until it reached the bottom of the step. The relative pressure then became negative until it reached the minimum negative pressure as it reached the top of the next step, and then the relative pressure began to increase. The reason for this is the vortex structure within the steps and the vortex caused the abnormal regularity of the internal pressure; the vortex at the bottom of the step rotated clockwise, and the centrifugal force was generated by the rotation at the bottom of the vertical surface of the step. The biggest clockwise vortex was near the vertical surface of the steps in a vertical orientation; this changed due to the fluctuation of the water. As the water vortex rotated away from the vertical surface of the step, negative pressure occurred on the vertical surface and the position where the minimum negative pressure is at 70 90\% of the step height. At the lower edge of the bottom of the upper step, the clockwise vortex met the incoming flow at that point, and a relatively large pressure occurred at that point. Under the other working conditions, the pressure distribution on the vertical surface of the different steps of the three types was similar to that shown in Figure 13. Under the working conditions with a high dam height, there were two areas for type 1 with negative pressure, which has been shown to be bimodal and type 2 and type 3 were unimodal with negative pressure in one area only.

4.5. Pressure along the Steps. The pressure distribution along the three types of spillway is shown in Figure 14. It can be seen from the figure that the distribution law of the relative pressure on the horizontal plane of the steps displays an oscillating pattern along the step. Since this optimization model focused on the initial step, it can be seen that the pressure for the type 2 and 3 spillways fluctuated more at the initial step than in type 1 , and the fluctuation along the path gradually became stable. The type 1 spillway displayed a wide negative pressure area along the steps.

4.6. Energy Dissipation Analysis. The energy dissipation rates for the two types of stepped spillway under the three working conditions were calculated using equations (1)-(4), and the results are shown in Tables 6 and 7 .

It can be seen from Tables 6 and 7 that the energy dissipation rate decreased with the increase in the unit 


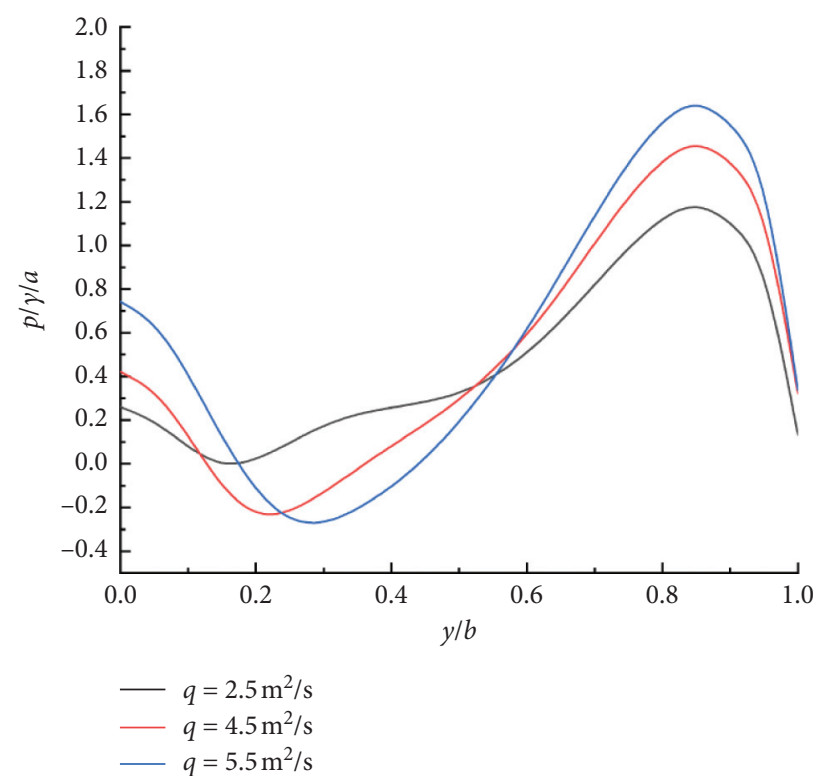

(a)

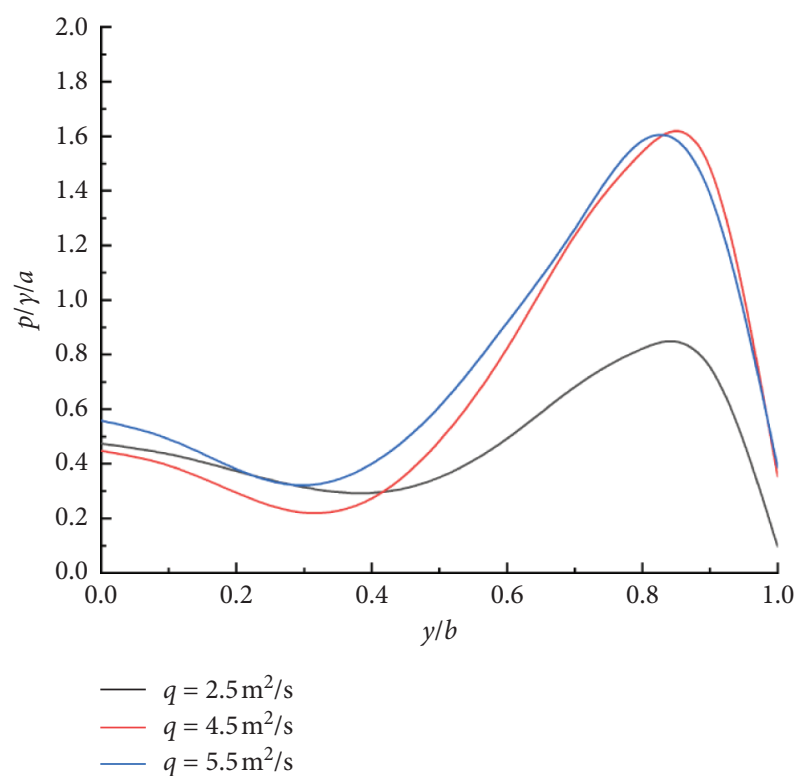

(b)

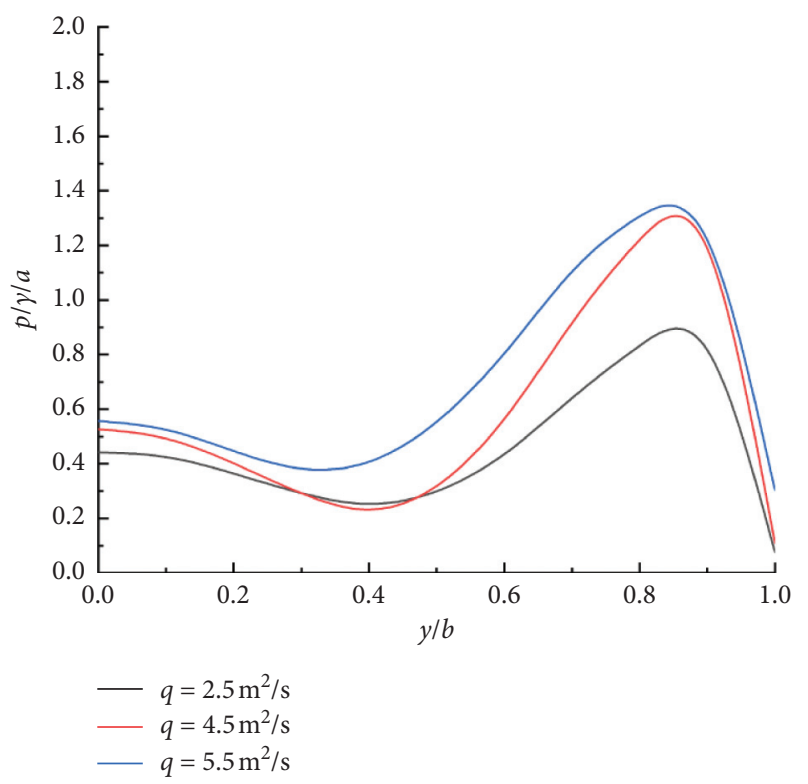

(c)

Figure 12: Pressure distribution of step $20(H=30 \mathrm{~m})$ : (a) type 1; (b) type 2; (c) type 3.

width discharge and increased with the increase in the height of the dam. The reason for this is that, as the flow rate increases and the energy dissipation rate of the step's energy dissipation section is less for the incoming flow, the energy dissipation rate is smaller. As the dam height increased, the length of the stepped spillway increased, and as a result, the energy dissipation distance for the incoming flow was longer, and therefore a higher energy dissipation rate was produced.
The energy dissipation rate of the optimal spillways of types 2 and 3 is around $80 \%$. For most dam heights and flow rates, the energy dissipation rate for a large flow rate is significantly higher for types 2 and 3 than that for type 1 . This has solved the problem where the overall energy dissipation rate of a stepped spillway of a dam on the Loess Plateau is lower due to the low energy dissipation rate in the initial stage. The energy dissipation rate is the best for a high dam and low flow, and the maximum energy dissipation rate reached $87.75 \%\left(H=45 \mathrm{~m}\right.$ and $\left.q=2.5 \mathrm{~m}^{2} / \mathrm{s}\right)$. 

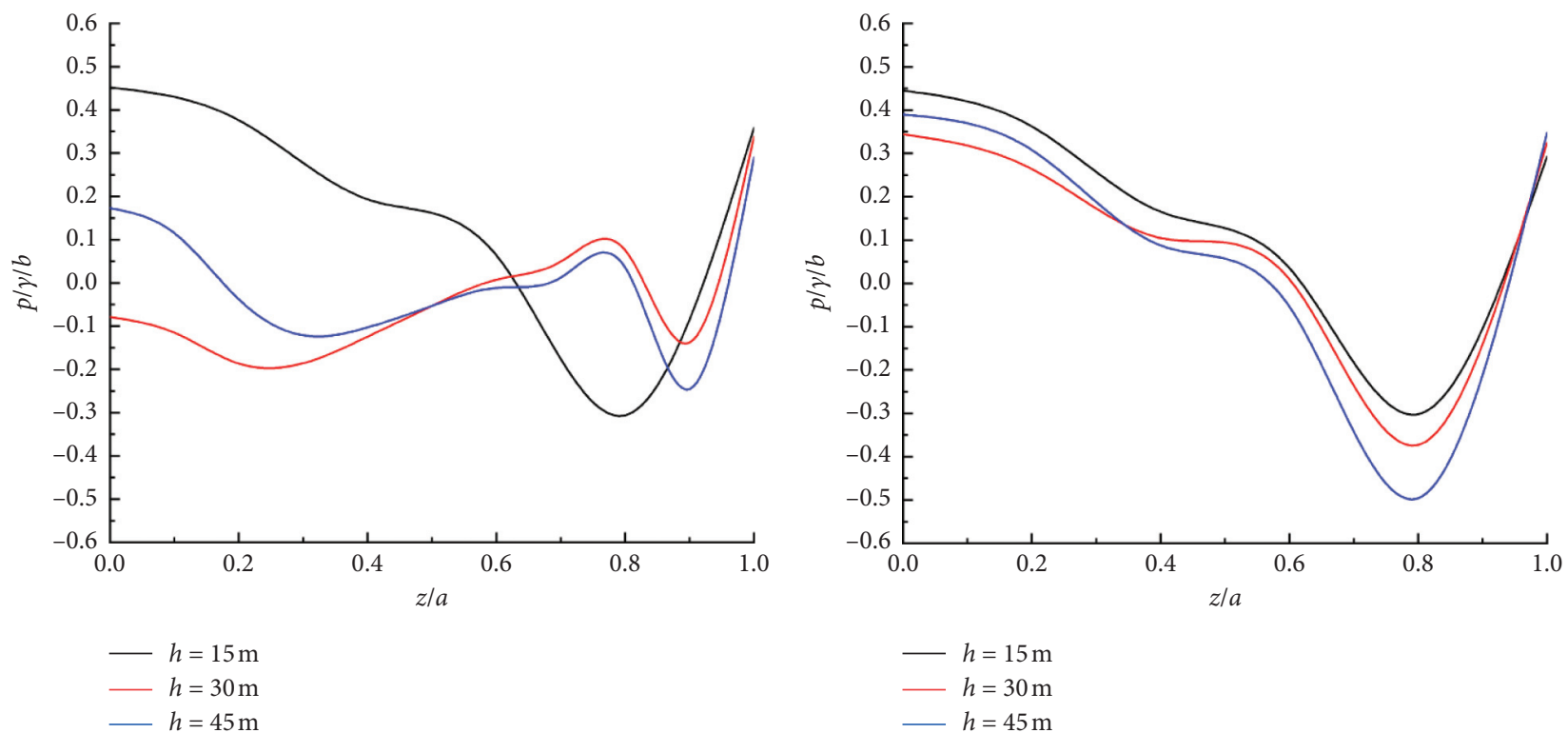

(a)

(b)

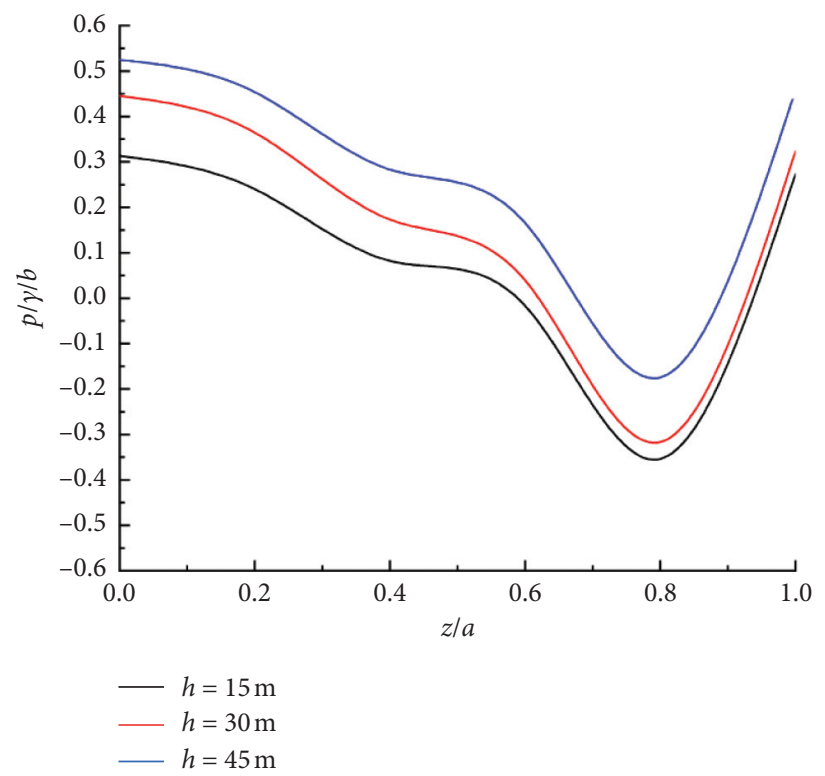

(c)

Figure 13: Pressure distribution of step $30\left(q=4.5 \mathrm{~m}^{2} / \mathrm{s}\right)$ : (a) type 1; (b) type 2; (c) type 3 .

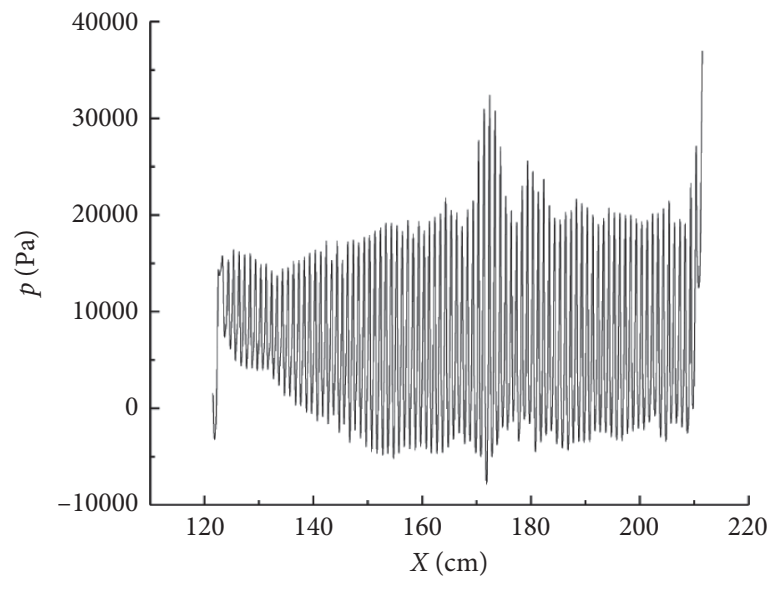

(a)

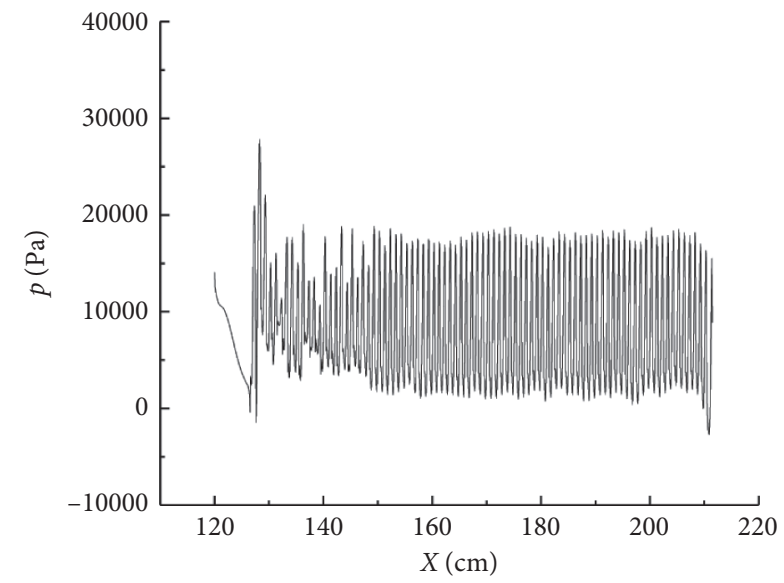

(b)

Figure 14: Continued. 


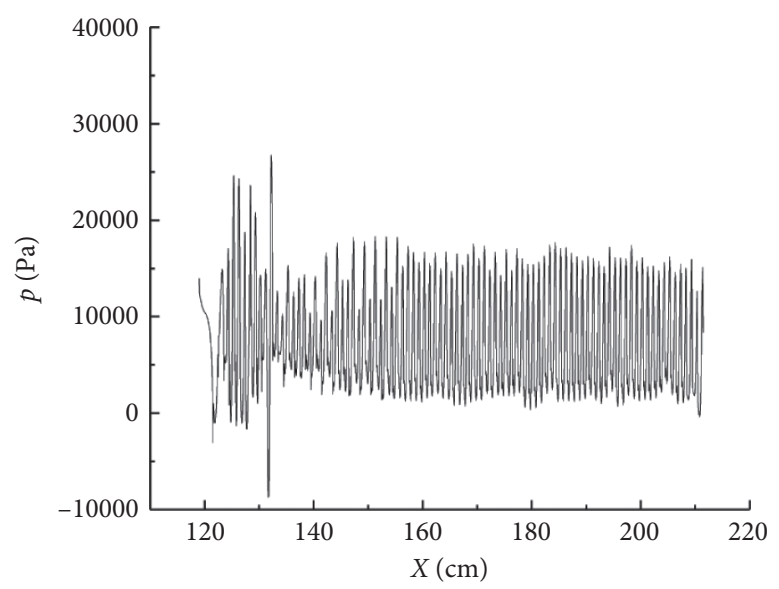

(c)

Figure 14: Pressure distribution along the three types of spillway $\left(H=45 \mathrm{~m}\right.$ and $\left.q=5.5 \mathrm{~m}^{2} / \mathrm{s}\right)$ : (a) type 1; (b) type 2; (c) type 3 .

TABLE 6: Calculation results of the energy dissipation rate of the type 2 spillway.

\begin{tabular}{|c|c|c|c|c|c|c|c|}
\hline Type & $\begin{array}{c}\text { Dam } \\
\text { height }(m)\end{array}$ & $\begin{array}{c}\text { Unit width } \\
\text { discharge }\left(\mathrm{m}^{2} / \mathrm{s}\right)\end{array}$ & $\begin{array}{c}\text { Weir crest } \\
\text { velocity, } v_{1}(\mathrm{~m} / \mathrm{s})\end{array}$ & $\begin{array}{c}\text { Terminal } \\
\text { velocity }(\mathrm{m} / \mathrm{s})\end{array}$ & $\begin{array}{l}\text { Terminal water } \\
\text { depth }(\mathrm{m})\end{array}$ & $\begin{array}{l}\text { Terminal Froude } \\
\text { number, Fr }\end{array}$ & $\begin{array}{c}\text { Energy dissipation } \\
\text { rate, } \eta\end{array}$ \\
\hline \multirow{9}{*}{2} & \multirow{3}{*}{$H=15$} & 2.5 & 1.900 & 8.299 & 0.290 & 4.92 & 78.72 \\
\hline & & 4.5 & 2.312 & 12.077 & 0.383 & 6.23 & 56.82 \\
\hline & & 5.5 & 2.472 & 12.722 & 0.428 & 6.21 & 52.96 \\
\hline & \multirow{3}{*}{$H=30$} & 2.5 & 1.900 & 9.552 & 0.264 & 5.94 & 85.24 \\
\hline & & 4.5 & 2.312 & 12.892 & 0.412 & 6.41 & 73.71 \\
\hline & & 5.5 & 2.472 & 13.796 & 0.432 & 6.70 & 70.19 \\
\hline & \multirow{3}{*}{$H=45$} & 2.5 & 1.900 & 12.585 & 0.226 & 8.45 & 82.64 \\
\hline & & 4.5 & 2.312 & 14.205 & 0.361 & 7.55 & 78.22 \\
\hline & & 5.5 & 2.472 & 14.679 & 0.409 & 7.33 & 76.90 \\
\hline
\end{tabular}

TABLe 7: Calculation results of the energy dissipation rate of the type 3 spillway.

\begin{tabular}{|c|c|c|c|c|c|c|c|}
\hline Type & $\begin{array}{c}\text { Dam } \\
\text { height }(\mathrm{m})\end{array}$ & $\begin{array}{c}\text { Unit width } \\
\text { discharge }\left(\mathrm{m}^{2} / \mathrm{s}\right)\end{array}$ & $\begin{array}{c}\text { Weir crest } \\
\text { velocity, } v_{1}(\mathrm{~m} / \mathrm{s})\end{array}$ & $\begin{array}{c}\text { Terminal } \\
\text { velocity }(\mathrm{m} / \mathrm{s})\end{array}$ & $\begin{array}{l}\text { Terminal water } \\
\text { depth }(\mathrm{m})\end{array}$ & $\begin{array}{c}\text { Terminal Froude } \\
\text { number, Fr }\end{array}$ & $\begin{array}{c}\text { Energy dissipation } \\
\text { rate, } \eta\end{array}$ \\
\hline \multirow{9}{*}{3} & \multirow{3}{*}{$H=15$} & 2.5 & 1.900 & 7.685 & 0.329 & 4.28 & 81.76 \\
\hline & & 4.5 & 2.312 & 9.308 & 0.458 & 4.39 & 74.35 \\
\hline & & 5.5 & 2.472 & 11.874 & 0.485 & 5.44 & 59.02 \\
\hline & \multirow{3}{*}{$H=30$} & 2.5 & 1.900 & 8.946 & 0.298 & 5.23 & 87.05 \\
\hline & & 4.5 & 2.312 & 12.154 & 0.383 & 6.27 & 76.63 \\
\hline & & 5.5 & 2.472 & 13.417 & 0.469 & 6.26 & 71.80 \\
\hline & \multirow{3}{*}{$H=45$} & 2.5 & 1.900 & 10.571 & 0.248 & 6.77 & 87.75 \\
\hline & & 4.5 & 2.312 & 13.078 & 0.354 & 7.02 & 81.54 \\
\hline & & 5.5 & 2.472 & 14.085 & 0.405 & 7.07 & 78.73 \\
\hline
\end{tabular}

\section{Conclusions}

In this paper, three types of stepped spillway energy dissipation schemes have been proposed based on the concept of fullsection water flow and distributed energy dissipation. This was aimed at the characteristics of small flow, low dam height, and short overflow length of the warping dams on the Loess Plateau among which two schemes (type 2 and 3 ) showed deformation of the shape of the initial steps. The numerical simulation software Ansys Fluent was used to simulate the stepped spillways of different types. By analyzing the flow pattern, the pressure distribution, and the energy dissipation effect of the different types of spillway, the following results were obtained: (i) When the water flow passes through the platform stage, an obvious stratification phenomenon appears. A stable clockwise vortex is produced between the vertical and horizontal faces of the steps, and there is a large amount of momentum exchange between the main flow and the vortices. This effect increases the dissipation rate of the turbulent kinetic energy, therefore achieving better energy dissipation. The flow patterns of the type 2 and 3 spillways along the path have shown that the mixing of the water in the initial steps is obvious, while the fluctuations of the surface of the water for type 1 are not. 
(ii) The change in the pressure over the step was consistent with the streamline in the gap between the steps. The pressure along the length of the step displayed a wave distribution pattern, and the crest and trough of the wave occur on the adjacent step, and the amplitude of the fluctuations decreased along the length of the step. The pressure distributions of the type 2 and 3 spillways were better than that of the type 1 spillway; they had fewer pressure fluctuations and fewer areas of negative pressure.

(iii) Compared with the type 1 spillway, the type 2 and type 3 spillways showed an improved energy dissipation rate throughout the entire working conditions. This was especially the case for large flow rates, where the maximum energy dissipation rate was increased by $27.97 \%\left(H=15 \mathrm{~m}\right.$ and $q=4.5 \mathrm{~m}^{2} /$ $\mathrm{s})$. The results have shown that this can compensate for the defects of the traditional layout of a spillway where the overall energy dissipation rate is low due to the low energy dissipation rate in the initial steps.

\section{Nomenclature}

\author{
$P: \quad$ Convergence accuracy \\ $F_{s}:$ Safety factor \\ Q: Flow rate $\left(\mathrm{kg} / \mathrm{m}^{3}\right)$ \\ $F_{r}$ : The number of Froude \\ $Z_{1}$ : Elevation of the upstream section $(\mathrm{m})$ \\ $R: \quad$ Ratio of grid size \\ $H_{1}$ : Upstream water level $(\mathrm{m})$ \\ $\eta$ : $\quad$ Energy dissipation rate \\ $\mathrm{H}_{2}$ : Downstream water level (m) \\ $\alpha$ : Velocity coefficient \\ $\nu_{1}$ : Average upstream speed $(\mathrm{m} / \mathrm{s})$ \\ $\theta: \quad$ Slope angle \\ $\nu_{2}$ : Average downstream speed $(\mathrm{m} / \mathrm{s})$ \\ $\gamma$ : Unit weight of water $(\mathrm{kg} / \mathrm{m})$ \\ $E_{1}$ : Total inlet energy $(\mathrm{J})$ \\ a: $\quad$ Step height $(\mathrm{m})$ \\ $E_{2}$ : Total outlet energy (J) \\ $b$ : $\quad$ Step width $(\mathrm{m})$.
}

\section{Data Availability}

The data used to support the findings of this study are available from the corresponding author upon request.

\section{Conflicts of Interest}

The authors declare that they have no conflicts of interest regarding the publication of this paper.

\section{Acknowledgments}

This research was supported by the Science and Technology Projects of Shaanxi Water Conservancy Department (grant no. 2017slkj-17) and National Natural Science Foundation of China (grant no. 51579206).

\section{References}

[1] Y. H. Cui, D. S. Xie, K. H. Yang, and J. G. Liu, "Test of overflow spillway with geomembrane liner built on an earth check dam," Journal of China Institute of Water Resources Hydropower Research, vol. 4, no. 1, pp. 42-46, 2006.

[2] C. Y. Zheng, "A brief discussion on the effective type of asphalt overlay for earth dam," Jilin Water Resources, vol. 10, pp. 22-23, 2010.

[3] R. J. Chen, "Ecological design for overflow earth dam of Mumianli reservoir," Guangxi Water Resources \& Hydropower Engineering, vol. 4, pp. 56-58, 2010.

[4] S.-R. Sabbagh-Yazdi and M. Misaghian, "Effect of water infiltration through concrete block spillways on the slope stability of earth overflow dams," European Journal of Environmental and Civil Engineering, vol. 21, no. 9, pp. 1114-1127, 2017.

[5] P. D. A. Manso and A. J. Schleiss, "Stability of concrete macroroughness linings for overflow protection of earth embankment dams," Canadian Journal of Civil Engineering, vol. 29, no. 5, pp. 762-776, 2002.

[6] G. L. Rubinshtein and G. V. Stefanovich, "Overflow earth dam with a stepped downstream face," Hydrotechnical Construction, vol. 32, no. 10, pp. 592-598, 1998.

[7] C. C. Wu, "An analysis of two-dimensional steady seepage flow of earth dam based on FEM," Advanced Materials Research, vol. 446-449, pp. 2699-2702, 2012.

[8] Q. B. Luo, S. J. Guo, and W. Tang, "Summary of overflow earth dam," Water Conservancy Science and Technology and Economy, vol. 16, no. 9, pp. 1023-1025, 2010.

[9] W. Z. Xing and S. L. Fang, "Research on the application of flexible material in overflow earth dam," Yangtze River, vol. 9, pp. 21-23, 2001.

[10] A. M. Zheng, Z. C. Zhang, and L. X. Tan, "Review on advance in stepped spillway studies," Journal of Shaanxi Water Power, vol. 4, pp. 18-21, 2000.

[11] A. Kaouachi, R. F. Carvalho, S. Benmamara, and M. Gafsi, "Numerical assessment of the inception point in different stepped spillway configurations," Arabian Journal of Geosciences, vol. 12, no. 18, p. 564, 2019.

[12] Z. Bai and J. Zhang, "Comparison of different turbulence models for numerical simulation of pressure distribution in V-shaped stepped spillway," Mathematical Problems in Engineering, vol. 2017, Article ID 3537026, 9 pages, 2017.

[13] S. Li, Q. Li, and J. Yang, "CFD modelling of a stepped spillway with various step layouts," Mathematical Problems in Engineering, vol. 2019, Article ID 6215739, 11 pages, 2019.

[14] J.-H. Wu, B. Zhang, and F. Ma, "Inception point of air entrainment over stepped spillways," Journal of Hydrodynamics, vol. 25, no. 1, pp. 91-96, 2013.

[15] A. Eghbalzadeh and M. Javan, "Comparison of mixture and VOF models for numerical simulation of air-entrainment in skimming flow over stepped spillways," Procedia Engineering, vol. 28, no. 4, pp. 657-660, 2012.

[16] D. Kositgittiwong, C. Chinnarasri, and P. Y. Julien, "Numerical simulation of flow velocity profiles along a stepped spillway," ARCHIVE Proceedings of the Institution of Mechanical Engineers Part E Journal of Process Mechanical Engineering, vol. 227, no. 4, pp. 327-335, 1996.

[17] H. Chanson and C. A. Gonzalez, "Physical modelling and scale effects of air-water flows on stepped spillways," Journal of Zhejiang University Science, vol. 6A, no. 3, pp. 243-250, 2005. 
[18] S. Felder and H. Chanson, "Air-water flow properties in step cavity down a stepped chute," International Journal of Multiphase Flow, vol. 37, no. 7, pp. 732-745, 2011.

[19] J. N. Tian, "The research on energy dissipation on stepped spillways," Journal of Xi'an University of Technology, vol. 4, pp. 346-350, 2002.

[20] J. N. Tian, "The characters of energy dissipation under different flows on stepped spillways," Journal of Hydraulic Engineering, vol. 4, pp. 35-39, 2003.

[21] J. N. Tian, "Energy dissipation in nappe flow on stepped spillways," Journal of Hydrodynamics, vol. 1, pp. 114-119, 2004.

[22] F. Salmasi and A. Samadi, "Experimental and numerical simulation of flow over stepped spillways," Applied Water Science, vol. 8, no. 8, p. 229, 2018.

[23] Z. C. Zhang, D. Y. Zeng, and A. M. Zheng, "Experimental investigation on the pressure characteristics of skimming flow on stepped spillways," Journal of Hydrodynamics, vol. 5, pp. 652-659, 2003.

[24] A. Mojtahedi, N. Soori, and M. Mohammadian, "Energy dissipation evaluation for stepped spillway using a fuzzy inference system," SN Applied Sciences, vol. 8, pp. 173-190, 2020.

[25] A. Azman, F. C. Ng, M. H. Zawawi et al., "Effect of barrier height on the design of stepped spillway using smoothed particle hydrodynamics and particle image velocimetry," KSCE Journal of Civil Engineering, vol. 24, no. 2, pp. 451-470, 2020.

[26] P. J. Roache, "Quantification of uncertainty in computational fluid dynamics," Annual Review of Fluid Mechanics, vol. 29, no. 29, pp. 123-160, 1997. 